\title{
Journal of Occupational Therapy Education
}

Interweaving Teaching Strategies in Interprofessional Education: A Pilot Study with Graduate Occupational Therapy and Physician Assistant Students

Eric C. Nemec II

Sacred Heart University

Lola Halperin

Sacred Heart University

Jaimee Hegge

Follow this and additional works at: https://encompass.eku.edu/jote

Part of the Occupational Therapy Commons

\section{Recommended Citation}

Nemec, E. C., Halperin, L., \& Hegge, J. (2021). Interweaving Teaching Strategies in Interprofessional Education: A Pilot Study with Graduate Occupational Therapy and Physician Assistant Students. Journal of Occupational Therapy Education, 5(1). https://doi.org/10.26681/jote.2021.050114

This Educational Innovations is brought to you for free and open access by the Journals at Encompass. It has been accepted for inclusion in Journal of Occupational Therapy Education by an authorized editor of Encompass. For more information, please contact Linda.Sizemore@eku.edu. 


\title{
Interweaving Teaching Strategies in Interprofessional Education: A Pilot Study with Graduate Occupational Therapy and Physician Assistant Students
}

\author{
Abstract \\ The importance of interprofessional education (IPE) has been emphasized by the World Health \\ Organization and is currently required by both the occupational therapy (OT) and physician assistant (PA) \\ education accreditation agencies in the United States. Moreover, a growing body of evidence suggests \\ that IPE fosters learners' understanding of the roles different disciplines play in healthcare delivery and \\ prepares future health professionals for patient-centered care. Authors designed and implemented an IPE \\ event aimed to foster the following core Interprofessional Education Collaborative (IPEC) competencies \\ among graduate OT and PA students: Values/Ethics for Interprofessional Practice, Roles and \\ Responsibilities, Interprofessional Communication, and Teams and Teamwork. The specific content of \\ this event addressed pharmacological and non-pharmacological treatment for older adult clients with \\ complex clinical presentation (with emphasis on OT- and PA- specific clinical interventions) and \\ incorporated a discussion of a clinical case study. Team-Based Learning approach, Jigsaw technique and \\ role-play were used as teaching strategies during this activity. Students' perceptions of IPE were \\ measured by administering the Students Perceptions of Interprofessional Clinical Education Revised \\ (SPICE-R) survey before and after the IPE event. This project is unique, because it incorporates a novel \\ combination of teaching strategies to augment the IPE experience.
}

\section{Keywords}

Interprofessional education, team-based learning, Jigsaw technique, simulated learning, occupational therapy, physician assistant studies

\section{Creative Commons License}

\section{c) (i) $\ominus$}

This work is licensed under a Creative Commons Attribution-Noncommercial-No Derivative Works 4.0 License.

\section{Acknowledgements}

This IPE experience was funded by the Sacred Heart University College of Nursing and College of Health Professions Interprofessional Education Award. The authors would like to thank Prof. Qarib Ahmed, Prof. Moira Ethier, Dr. Sharon McCloskey, Prof. Sandy Narciso-Owen, and Prof. Morgan Villano, Sacred Heart University, for their assistance in facilitating the IPE event; and Dr. Jacqueline Vernarelli, PhD, for her assistance with copyediting. 


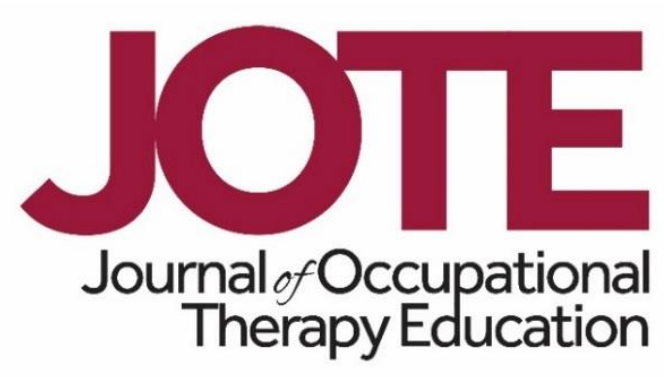

Volume 5, Issue 1

\title{
Interweaving Teaching Strategies in Interprofessional Education: A Pilot Study with Graduate Occupational Therapy and Physician Assistant Students
}

\author{
Eric Nemec, PharmD \\ Lola Halperin, EdD, OTR/L \\ Jaimee M.B. Hegge, OTD, OTR/L \\ Sacred Heart University \\ United States
}

\begin{abstract}
The importance of interprofessional education (IPE) has been emphasized by the World Health Organization and is currently required by both the occupational therapy (OT) and physician assistant (PA) education accreditation agencies in the United States. Moreover, a growing body of evidence suggests that IPE fosters learners' understanding of the roles different disciplines play in healthcare delivery and prepares future health professionals for patient-centered care. Authors designed and implemented an IPE event aimed to foster the following core Interprofessional Education Collaborative (IPEC) competencies among graduate OT and PA students: Values/Ethics for Interprofessional Practice, Roles and Responsibilities, Interprofessional Communication, and Teams and Teamwork. The specific content of this event addressed pharmacological and non-pharmacological treatment for older adult clients with complex clinical presentation (with emphasis on OT- and PA- specific clinical interventions) and incorporated a discussion of a clinical case study. TeamBased Learning approach, Jigsaw technique and role-play were used as teaching strategies during this activity. Students' perceptions of IPE were measured by administering the Students Perceptions of Interprofessional Clinical Education Revised (SPICE-R) survey before and after the IPE event. This project is unique, because it incorporates a novel combination of teaching strategies to augment the IPE experience.
\end{abstract}




\section{Background and Introduction}

\section{Interprofessional Education and Student Perceptions}

According to the World Health Organization (WHO), "effective interprofessional education is necessary in order to prepare a health workforce that is ready for effective collaborative practice, to improve health outcomes" (WHO, 2010, p.7). Interprofessional education (IPE) for entry-level occupational therapy (OT) students is currently emphasized in the Accreditation Council for Occupational Therapy Education (ACOTE) standards (ACOTE, 2019). The Accreditation Review Commission on Education for the Physician Assistant (ARC-PA) similarly acknowledges ongoing changes in health professional training and highlights the importance of teaching interprofessional collaboration skills to Physician Assistant (PA) students (ARC-PA, 2019). Both OT and PA accreditation agencies have previously incorporated at least one standard about interprofessional practice (Zorek \& Raehl, 2013). While embracing the principles of IPE, it is likely important to preserve and encourage the leverage of each discipline's unique elements within their respective scopes of practice (Yancey et al., 2018).

The Interprofessional Education Collaborative (IPEC, 2016) has identified four core competencies pertaining to healthcare education as essential to success in the current healthcare environment: Values/Ethics for Interprofessional Practice (e.g., respecting and cooperating with both patients and various disciplines involved in their care), Roles and Responsibilities (e.g., understanding discipline-specific as well as interdisciplinary contributions to patient care), Interprofessional Communication (e.g., interacting with patients and other disciplines in ways that enhance team function), and Teams and Teamwork (e.g., involving patients and other disciplines in problem solving and decision-making in regards to patient care; IPEC, 2016).

In an effort to train future health professionals in these competencies, it is recommended that academic institutions utilize IPE events, during which two or more disciplines can learn together, from and about each other (WHO, 2010). There are a number of recent reports of successful IPE events involving OT and PA students as members of inter-disciplinary learner teams (Buhler et al., 2011; Guadagnoli \& Miller, 2016; Hadley et al., 2018; Kim et al., 2019; Shoemaker et al., 2014; Weidman-Evans et al., 2017). Buhler et al. (2011) described an interprofessional event for students in five different health professions programs, including OT and PA. The post survey revealed an overwhelming agreement among the respondents that "interprofessional approaches have advantages to monoprofessional approaches and interprofessional practice is important in producing effective therapeutic outcomes" (p. 224).

However, preliminary research has also shown potential interdisciplinary differences pertaining to attitudes about interprofessional collaboration among healthcare students, with some evidence suggesting that OT students might be more open to the interprofessional experiences than their peers from other disciplines, e.g., nursing and physical therapy (PT; Avrech Bar et al., 2018) or PA (Hertweck et al., 2012). Hertweck et al. (2012) also reported gender discrepancies in terms of student perceptions pertaining to IPE, with female students exhibiting more positive attitudes towards it. 


\section{IPE Pedagogies}

Various pedagogies have been used to facilitate interprofessional learning among healthcare students. For instance, Guadagnoli and Miller (2016) reported on the use of a Team-Based Learning (TBL) approach while conducting an IPE activity at Touro University, Nevada. TBL is an evidence-based teaching methodology that involves learning in small teams and incorporates individual learner preparation, in-class readiness assurance tests and team problem-solving of application exercises (TBL Collaborative, 2020). The TBL approach has been shown to increase confidence and critical thinking among PA students (Loftin \& West, 2017) and has been linked to higher student satisfaction in OT education (Carson, 2017). Moreover, according to Guadagnoli and Miller (2016), the IPE activity facilitated in a TBL format proved to be efficient in enhancing students' understanding of other professions' roles in healthcare.

The work of Hadley et al. (2018) is of a particular interest, as it incorporated an innovative teaching methodology called a "Jigsaw technique" into the IPE activity the authors conducted with 53 students representing the OT, PA, PT, and pharmacy programs at the University of the Sciences (USciences), Philadelphia. The Jigsaw technique has been previously shown to be effective in familiarizing medical students with various healthcare professions (Buhr et al., 2014). The IPE experience facilitated by Hadley et al. (2018) consisted of an icebreaker activity (discussion of the scope of practice of the participating disciplines), a refreshment break, discipline-specific group discussions of a clinical case run by respective discipline facilitators, an interprofessional brainstorming of a potential discharge plan for the client portrayed in the clinical case, a simulation of an interprofessional team counseling the "client" (roleplayed by a faculty member) and a large group debriefing. "Jig-sawing" between their original professional and assigned interprofessional groups allowed the students to feel comfortable analyzing the case presented to them in a familiar environment prior to representing their discipline in a mixed, interprofessional group. The student survey, which was conducted after the IPE activity was completed, revealed that students from different disciplines appreciated the opportunity to communicate and collaborate with each other, and that the activity stimulated their respect towards each other's professions, and their readiness for patient-centered practice.

Simulated learning is currently also playing an increasing role in healthcare education (Fusco \& Foltz-Ramos, 2018; Gibbs et al., 2017; Society for Simulation in Healthcare, 2020; Van Soeren et al., 2011). For instance, Gibbs et al. (2017) reported that clinical simulation significantly increased OT students' "perceived knowledge, confidence and comfort in an acute care setting, and their interest in this setting for future employment" (p.11). Simulated learning can be successfully assisted by utilization of patient actors in order to create a "safe and controlled environment" for the learners to practice clinical skills and receive feedback (Haracz et al., 2015, p. 758). Utilization of patient actors increases students' satisfaction with simulated learning activities by making these activities more enjoyable and by allowing students to receive feedback from the actors (Haracz et al., 2015). 


\section{Current Study}

The goal of the current project was to assess whether a combination of TBL, Jigsaw technique, and clinical simulation during an IPE event would enhance perceptions of the core interprofessional competencies among OT and PA students. To the best of our knowledge, this is the first effort to evaluate the above combination of pedagogies in OT and PA training.

\section{Description of the IPE Activity}

This IPE experience actively engaged 59 first-year graduate OT students and 39 graduate PA students to learn about and debate pharmacological versus nonpharmacological treatment modalities available to older adult clients affected by multiple comorbidities, and incorporated a discussion of a sample clinical case portraying a client with Bipolar Disorder, Mild Neurocognitive Disorder (MND), chronic pain, polypharmacy, and opioid misuse. The similarities and differences between the OT and PA professions in terms of treating clients with the above conditions were brainstormed and students were invited to problem-solve specific scenarios pertaining to the clinical case in small groups. This project was sponsored by the Sacred Heart University College of Health Professions Interprofessional Education grant.

Investigators used a novel combination of three innovative pedagogies to facilitate this IPE event: TBL approach, clinical simulation, and the Jigsaw technique. The IPE event lasted for approximately 3.5 hours and consisted of seven parts: an icebreaker trivia; individual and team readiness assessment tests (iRAT and tRAT) in discipline-specific small groups; a refreshment break; a mini-lecture; problem-solving in small interprofessional groups; a role-play/patient actor feedback, and debriefing. An outline of the event schedule can be found in Table 1.

\section{Table 1}

\begin{tabular}{cl} 
IPE Event Schedule & \\
\hline 4:30-4:45 PM & Introduction and Trivia \\
4:45-5:15 PM & Individual and Team Readiness Assessment Tests (in discipline- \\
5:15-5:30 PM & specific groups) \\
5:30-6:00 PM & Mini-Lecture \\
6:00-7:00 PM & Application Activity (in interprofessional groups) \\
7:00-7:15 PM & Role-Play \\
7:15-7:30 PM & Discussion and debrief \\
7:30-8:00 PM & Dinner \\
\hline
\end{tabular}

Students were assigned discipline-specific reading materials prior to the IPE experience. Additionally, students received an email invitation to complete a pre/post survey instrument two weeks prior to attending the event; they were also asked to complete the survey one week after the event. Students who completed both surveys were entered into a drawing to win one of ten $\$ 25$ gift cards. The study was approved by the university Institutional Review Board (IRB) and all survey respondents provided informed consent to participate. 
A trivia activity related to the roles of OTs and PAs within the healthcare system served as an icebreaker and was facilitated for the first 15 min of the session. During the icebreaker, the PA students were asked questions about OT scope of practice, certification/licensure regulations and practice settings; and OT students were asked similar questions about the PA profession.

Next, the participants took the iRAT and tRAT in discipline-specific groups of approximately eight students. In accordance with the TBL methodology, the iRAT and tRAT consisted of six multiple choice questions, and the students were presented with the same questions when working both individually and in groups. The tests covered content pertaining to MND, bipolar illness, chronic pain symptomatology, and respective treatments. Additionally, OT students were quizzed on the OT interventions pertaining to the clinical case, and PA students were quizzed on the relevant pharmacology. The above information had been covered in the academic semester courses and was reinforced by the readings the students were assigned prior to the IPE event. The students took the iRAT individually but collaborated within their discipline-specific groups during the tRAT. When working as a team, the students used the Immediate Feedback Assessment Technique (IF-AT) "scratch-off" sheets (Epstein Educational Enterprise, 2020) while attempting to find a star that indicated a correct answer to each test question. The iRAT and tRAT were incorporated into this IPE experience because they are essential components of the TBL methodology and help assure students' preparation prior to the TBL activity as well as teamwork during it (TBL Collaborative, 2020).

The tests took 30 minutes in total and were followed by a 15-minute refreshment break. A 30-minute mini-lecture was presented by the OT and PA faculty members right after the break. The PA faculty emphasized the pharmacological management of MND, Bipolar Disorder, and chronic pain, and the OT faculty presented on the nonpharmacological treatment modalities, with an emphasis on motivational interviewing and OT-specific interventions for clients affected by these conditions. This content was prepared and aligned with the iRAT/tRAT questions by the OT and PA faculty presenters in advance.

After the mini-lecture, the students were asked to "jigsaw" from their discipline-specific groups into interprofessional groups, with some of the members in each group representing the OT program, and the others representing the PA program. The interprofessional groups were presented with five specific clinical scenarios involving the client in the clinical case and were asked to problem-solve these scenarios while selecting the best answer out of the multiple choices offered to them. The small group discussions were assisted by four OT and two PA faculty members.

This was followed by a large class discussion and a brief role-play of an OT/PA meeting with the "client" portrayed by a trained patient actor. The role play was scheduled at the end of the event to allow the students the opportunity to apply the new information they learned about OT and PA strategies for working with clients with complex clinical presentation. The actor had been provided with the details of the case in advance. The 
case described an older female diagnosed with MND, Bipolar illness, chronic pain, polypharmacy, opioid misuse, and a recent history of falls, who had not gotten out of bed to bathe in several days. During the role play the actor interacted with two students representing both disciplines within a mock assisted living facility room to simulate how interprofessional collaboration would occur in an inpatient setting, while the rest of the students observed this activity. The two students who volunteered for the role play elicited additional history from the "client," evaluated her bed mobility and ambulation, and assessed her ability to follow simple one step directions. They also applied information presented during the mini lecture in the beginning of the IPE event to provide implicit cues to the client during motor tasks performance, facilitate safe mobility, and utilize motivational interviewing strategies while encouraging the client to get out of bed to bathe. The patient actor and faculty provided immediate feedback to the students on aspects of their performance that were successful and constructive feedback to help improve their clinical skills.

The problem-solving and discussion together took approximately $60 \mathrm{~min}$, and the roleplay and feedback lasted for about 15 min, which appeared to be sufficient and matched students' energy levels during this phase of the IPE event.

The participants were asked to debrief on the entire IPE experience during the remaining time. The debriefing allowed students to reflect on their learning process and interprofessional interactions during the event, and afforded faculty the opportunity to solicit feedback regarding the logistics of this learning experience. A light dinner was served at the end of the event.

\section{Data Collection and Analysis}

Investigators aimed to assess if the teaching methodologies employed in this project affected participating students' perceptions regarding interprofessional work. The Students Perceptions of Interprofessional Clinical Education Revised (SPICE-R) instrument was used in a pre-post survey study design to assess the impact of the IPE event. The SPICE-R instrument had been developed for assessing change in students' perceptions regarding various aspects of interprofessional cooperation pursuant to an educational intervention, and specifically validated to examine teamwork as well as roles/responsibilities in health professions students (Fike et al., 2013). The SPICE-R was selected for this study as the outcome measurement, since it has been previously used to measure students' perceptions about interdisciplinary work in health professions (Fike et al., 2013; Fusco \& Foltz-Ramos, 2018; Risling-de Jong et al., 2016; Rosenbloom \& Nemec, 2020), including those pursuing education in OT or PA (Manspeaker et al., 2017; Peeters et al., 2016; Wallace \& Benson, 2018).

Additionally, as part of the post-event survey, participants were asked to respond to two open questions regarding the teamwork and roles/responsibilities experienced during the event: 1 . "What were the two (or more) most significant things about working and/or communicating with your peers in the opposite discipline?" 2. "What did you learn about the roles and responsibilities of the opposite discipline (think about how you will work together in clinical practice)?" 
While participation in the event was a required course component, completion of the surveys was voluntary. Surveys were distributed using Qualtrics XM @ 2020 (Provo, UT), and Likert data collected were analyzed using paired sample t-tests in SPSS v25 (Armonk, NY). Qualitative data were exported from the survey responses and reviewed for general trends.

\section{Results}

Overall, the survey received 77 paired responses, yielding a $78.6 \%$ response rate. $A$ total of 9 of the 11 survey items when looking at the entire study population showed a statistically significant improvement compared to baseline (see Table 2). The two statements that did not reach significance were rated very highly at baseline and, given the graduate nature of the participating academic programs, it was not surprising to see the lack of change. The statements were: "Health outcomes are improved when patients are treated by a team that consists of individuals from two or more health professions" (4.68 vs. $4.73 ; p=.54$ ) and "Health professionals should collaborate on interprofessional teams" (4.63 vs. $4.70 ; p=.35)$. In addition to the overall analysis, investigators also examined subgroups of the data based on both discipline (see Table 3) and gender.

Table 2

Overall Event Combined SPICE- $R$ Pre-Post Statistics $(N=77)$

\begin{tabular}{|l|c|c|c|}
\hline \multicolumn{1}{|c|}{ SPICE-R Items } & $\begin{array}{c}\text { Pre- } \\
\text { Mean } \\
\text { (SD) }\end{array}$ & $\begin{array}{c}\text { Post- } \\
\text { Mean } \\
\text { (SD) }\end{array}$ & p-value \\
\hline $\begin{array}{l}\text { 1. Working with students from another health } \\
\text { profession enhances my education }\end{array}$ & $\begin{array}{c}3.95 \\
(0.82)\end{array}$ & $\begin{array}{c}4.48 \\
(0.64)\end{array}$ & $<.001$ \\
\hline $\begin{array}{l}\text { 2. My role within an interprofessional healthcare team } \\
\text { is clearly defined }\end{array}$ & $\begin{array}{c}4.05 \\
(0.75)\end{array}$ & $\begin{array}{c}4.32 \\
(0.64)\end{array}$ & .017 \\
\hline $\begin{array}{l}\text { 3. Health outcomes are improved when patients are } \\
\text { treated by a team that consists of individuals from } \\
\text { two or more health professions }\end{array}$ & $\begin{array}{c}4.68 \\
(0.50)\end{array}$ & $\begin{array}{c}4.73 \\
(0.45)\end{array}$ & .54 \\
\hline $\begin{array}{l}\text { 4. Patient satisfaction is improved when patients are } \\
\text { treated by a team that consists of individuals from } \\
\text { two or more health professions }\end{array}$ & $\begin{array}{c}4.41 \\
(0.72)\end{array}$ & $\begin{array}{c}4.65 \\
(0.60)\end{array}$ & .03 \\
\hline $\begin{array}{l}\text { 5. Participating in educational experiences with } \\
\text { students from another health profession enhances } \\
\text { my future ability to work on an interprofessional } \\
\text { team }\end{array}$ & $\begin{array}{c}4.08 \\
(0.80)\end{array}$ & $\begin{array}{c}4.62 \\
(0.61)\end{array}$ & $<.001$ \\
\hline $\begin{array}{l}\text { 6. All health professional students should be } \\
\text { educated to establish collaborative relationships } \\
\text { with members of other health professions }\end{array}$ & $\begin{array}{c}4.51 \\
(0.60)\end{array}$ & $\begin{array}{c}4.69 \\
(0.49)\end{array}$ & .04 \\
\hline $\begin{array}{l}\text { 7. I understand the roles of other health professionals } \\
\text { within an interprofessional team }\end{array}$ & $\begin{array}{c}4.00 \\
(0.66)\end{array}$ & $\begin{array}{c}4.29 \\
(0.56)\end{array}$ & .004 \\
\hline $\begin{array}{l}\text { 8. Clinical rotations are the ideal place within their } \\
\text { respective curricula for health professional } \\
\text { students to interact }\end{array}$ & $\begin{array}{c}3.93 \\
(0.81)\end{array}$ & $\begin{array}{c}4.31 \\
(0.59)\end{array}$ & .001 \\
\hline
\end{tabular}




\begin{tabular}{|l|c|c|c|}
\hline 9. Health professionals should collaborate on & $\begin{array}{c}4.63 \\
(0.49)\end{array}$ & $\begin{array}{c}4.70 \\
(0.49)\end{array}$ & .35 \\
\hline $\begin{array}{l}\text { 10. During their education, health professional } \\
\text { students should be involved in teamwork with } \\
\text { students from other health professions in order to } \\
\text { understand their respective roles }\end{array}$ & $\begin{array}{c}4.28 \\
(0.63)\end{array}$ & $\begin{array}{c}4.58 \\
(0.55)\end{array}$ & .002 \\
\hline $\begin{array}{l}\text { 11. Working with a different discipline gave me insight } \\
\text { into how to better manage patients/clients with } \\
\text { neurocognitive disorders }\end{array}$ & $\begin{array}{c}3.85 \\
(0.93)\end{array}$ & $\begin{array}{c}4.60 \\
(0.54)\end{array}$ & $<.001$ \\
\hline
\end{tabular}

When stratifying by discipline (OT $n=48 ; P A n=29$ ), it was interesting to note that much of the overall significance was driven by the OT students' responses, which indicated a significant increase for each SPICE-R statement (See Table 3); whereas, seven of the PA responses were not significantly different.

\section{Table 3}

Discipline Specific SPICE-R Pre-Post Statistics (N=77)

\begin{tabular}{|l|c|c|c|c|}
\hline \multicolumn{1}{|c|}{ SPICE-R Items } & Program & $\begin{array}{c}\text { Pre Mean } \\
\text { (SD) }\end{array}$ & $\begin{array}{c}\text { Post Mean } \\
\text { (SD) }\end{array}$ & p-value \\
\hline $\begin{array}{l}\text { 1. Working with students } \\
\text { from another health } \\
\text { profession enhances my } \\
\text { education }\end{array}$ & PA & $3.77(0.97)$ & $4.32(0.75)$ & .015 \\
\cline { 2 - 5 } $\begin{array}{l}\text { 2. My role within an } \\
\text { interprofessional } \\
\text { healthcare team is clearly } \\
\text { defined }\end{array}$ & OT & $4.07(0.69)$ & $4.59(0.54)$ & $<.001$ \\
\cline { 2 - 5 } $\begin{array}{l}\text { 3. Health outcomes are } \\
\text { improved when patients } \\
\text { are treated by a team that } \\
\text { consists of individuals from } \\
\text { two or more health } \\
\text { professions }\end{array}$ & OT & $4.23(0.77)$ & $4.35(0.66)$ & .512 \\
\cline { 2 - 5 } $\begin{array}{l}4 . \text { Patient satisfaction is } \\
\text { improved when patients } \\
\text { are treated by a team that } \\
\text { consists of individuals from } \\
\text { two or more health } \\
\text { professions }\end{array}$ & OT & $4.93(0.72)$ & $4.30(0.63)$ & .01 \\
\cline { 1 - 5 } $\begin{array}{l}\text { 5. Participating in } \\
\text { educational experiences } \\
\text { with students from another } \\
\text { health profession } \\
\text { enhances my future ability } \\
\text { to work on an } \\
\text { interprofessional team }\end{array}$ & OT & $4.31(0.41)$ & $4.68(0.48)$ & .283 \\
\cline { 2 - 5 } & OT & $4.18(0.72)$ & $4.76(0.43)$ & .12 \\
\hline
\end{tabular}




\begin{tabular}{|c|c|c|c|c|}
\hline \multirow{2}{*}{$\begin{array}{l}\text { 6. All health professional } \\
\text { students should be } \\
\text { educated to establish } \\
\text { collaborative relationships } \\
\text { with members of other } \\
\text { health professions }\end{array}$} & PA & $4.53(0.51)$ & $4.52(0.57)$ & .901 \\
\hline & OT & $4.49(0.66)$ & $4.80(0.40)$ & .008 \\
\hline \multirow{2}{*}{$\begin{array}{l}\text { 7. I understand the roles of } \\
\text { other health professionals } \\
\text { within an interprofessional } \\
\text { team }\end{array}$} & PA & $4.00(0.74)$ & $4.29(0.59)$ & .095 \\
\hline & OT & $4.00(0.60)$ & $4.28(0.54)$ & .021 \\
\hline \multirow{2}{*}{$\begin{array}{l}\text { 8. Clinical rotations are the } \\
\text { ideal place within their } \\
\text { respective curricula for } \\
\text { health professional } \\
\text { students to interact }\end{array}$} & PA & $3.93(0.91)$ & $4.35(0.55)$ & .032 \\
\hline & OT & $3.93(0.75)$ & $4.28(0.62)$ & .017 \\
\hline \multirow{2}{*}{$\begin{array}{l}\text { 9. Health professionals } \\
\text { should collaborate on } \\
\text { interprofessional teams }\end{array}$} & PA & $4.73(0.45)$ & $4.55(0.57)$ & .163 \\
\hline & OT & $4.56(0.50)$ & $4.80(0.40)$ & .011 \\
\hline \multirow[b]{2}{*}{$\begin{array}{l}\text { 10. During their education, } \\
\text { health professional } \\
\text { students should be } \\
\text { involved in teamwork with } \\
\text { students from other health } \\
\text { professions in order to } \\
\text { understand their } \\
\text { respective roles }\end{array}$} & PA & $4.30(0.60)$ & $4.45(0.62)$ & .336 \\
\hline & OT & $4.27(0.65)$ & $4.67(0.47)$ & .001 \\
\hline \multirow{2}{*}{$\begin{array}{l}\text { 11. Working with a } \\
\text { different discipline gave } \\
\text { me insight into how to } \\
\text { better manage } \\
\text { patients/clients with } \\
\text { neurocognitive disorders }\end{array}$} & PA & $3.77(1.04)$ & $4.55(0.57)$ & .001 \\
\hline & OT & $3.91(0.85)$ & $4.63(0.53)$ & $<.001$ \\
\hline
\end{tabular}

There were also some differences when stratified by gender. Looking at the demographic breakdown of the event, OT respondents were $88 \%(n=42)$ female and PA respondents were $69 \%(n=20)$ female; overall, respondents were $80 \%$ female $(n=62)$. Gender demographics of the survey respondents were representative of the population when considering non-responders (e.g. the PA cohort were $79 \%$ female). When the analyses were stratified by gender, investigators noted that female participants had contributed the SPICE-R responses that had led to statistically significant differences in the overall combined results reported in Table 2. However, when analyzing male responses, none of the SPICE-R statements generated responses that had a statistically significant difference between the pre- and post-tests.

Investigators also reviewed the qualitative data elicited from the open comment boxes on the survey which yielded a number of informative trends. Almost all respondents $(97.5 \% ; n=75)$ provided some qualitative feedback. The first trend identified was that students reported a strong preference for this event encompassing two disciplines in 
contrast to the other interprofessional events attended by 8-10 disciplines they had participated in previously. Respondents indicated that the small group interactions afforded better opportunity for understanding the role and scope of the opposite discipline, again, in contrast to attempting to learn about many. While this may not always be feasible within a given institution, this trend was the primary finding to emerge from the data.

The second trend that emerged was that students appreciated the inclusion of cognitive domain learning aspect within the session. While the primary aim of the original project design was to improve perceptions of the core IPE competencies, students reported they valued the opportunity to acquire concrete knowledge as it offered more than the affective domain-driven learning outcomes expected at other IPE events they had attended previously.

\section{Discussion}

The present study was designed to assess whether a combination of innovative teaching methods (TBL, Jigsaw technique and clinical simulation) utilized during an IPE event would enhance the perceptions of core interprofessional competencies (Values/Ethics for Interprofessional Practice, Roles and Responsibilities, Interprofessional Communication, and Teams and Teamwork) among OT and PA students. This was a novel project, as the pedagogies it incorporated had not been evaluated when used in concert, nor had they been investigated when specifically working with OT and PA students on a team.

Overall, the combination of these pedagogies yielded a significant improvement in students' perceptions towards IPE competencies as measured by the SPICE-R instrument. However, it was also found that this improvement was more significant among OT students, potentially suggesting lower levels of readiness for interprofessional collaboration among PA students. This finding appears to be supported by the existing evidence. For instance, Hertweck et al. (2012) conducted a study to compare IPE readiness among PA, OT, PT, and counseling psychology students while using the Readiness for Interprofessional Learning Scale (RIPLS). According to these authors, PA students scored significantly lower than others on the Roles and Responsibilities, and Teamwork and Collaborations subscales of this tool as well as on its total value. The authors suggested these results may be attributed to the "attitudes and preconceived stereotypes regarding other health professions" among PA students, especially early in their educational journey (p.13). In the current study, this finding may also be attributed to the PA students' background, as they are required to have a minimum of 1000 paid patient care hours prior to applying for the program. When applying to the OT program, candidates are required to complete relevant volunteer or shadowing experiences, but there are no specific requirements about clinical settings or exposure to other disciplines. Therefore, it is plausible that the PA students had more experience working in an interprofessional setting and thus the impact on their perceptions pursuant to the IPE event was muted. 
Importantly, in the cited above study (Hertweck et al., 2012), females, younger students, and students who had had personal experience with receiving healthcare services demonstrated more positive attitudes towards interprofessional learning, teamwork, and collaboration in comparison to their peers who were either males, older, or less experienced with being a patient or a patient's family member. Most of the above findings had been supported by previous studies involving PA or medical students (Hertweck et al., 2012). Similarly, an unexpected outcome of our study was the contrast between female and male student responses to our survey. As we reported in the Results section, while female respondents demonstrated a significant change in their perceptions regarding interprofessional collaboration following the IPE event, no significant change was discovered among the male respondents. One could speculate that differences in attitudes towards interprofessional competencies could be attributed to distinct personality traits among females and males. Gender differences in personality traits have been previously documented in the literature, with women exhibiting higher levels of Agreeableness, Conscientiousness, and Openness to Experience than men (Schmitt et al., 2017; South et al., 2018), and Conscientiousness and Openness to Experience serving as predictors of leadership self-efficacy among females (Huszczo \& Endres, 2017). It is possible that higher prevalence of these characteristics among female students resulted in more willingness on their part to learn from the IPE event and, subsequently, in more substantial changes in their beliefs about interprofessional work as compared to their male counterparts. Additionally, genderspecific personality traits might also have contributed to the perception differences investigators observed between OT and PA students in the survey data following our event, as the majority of OT participants were female. The potential impact of genderdriven personality differences on students' IPE outcomes might require further exploration.

The above findings provide opportunities for reflection. Howell (2009) suggested that stereotypes among allied health students towards other disciplines negatively affect their mutual respect, trust, communication, and collaboration, and interfere with interprofessional education. Lack of training pertaining to interprofessional learning as well as differences in levels of education, professional philosophy, and terminology serve as additional barriers to working together successfully (Howell, 2009). Weller and Cumin (2014) suggested several strategies to improve team communication in healthcare, including training healthcare providers together, teaching them effective communication strategies, and creating inclusive teams rather than dividing by discipline. We recommend incorporating these concepts into future IPE events for students.

Howell's grounded theory (2009) highlighted the vital role of creating a culture of interdisciplinary respect in enhancing interprofessional education. A greater understanding of one's professional identity and clear articulation of it coupled with confidence and assertive communication can create an environment of mutual respect among healthcare professionals and help facilitate interprofessional collaboration (Howell, 2009). Assertive communication has also been researched in nursing literature and is correlated with promoting patient safety (Omura et al., 2017). 
Howell (2009) discovered that, as compared to students from a number of allied health disciplines who sometimes exhibited biased views towards other professions, OT students often lacked a sense of professional identity upon admission to their professional programs and reported that their skills progressed over time from representing their profession and asserting themselves in a team situation to working and problem solving within a team. Boehm et al. (2015) stipulated that professional identity of OT students develops during their entry-level education and fieldwork placements. While applicants in other allied health disciplines may be required to complete a specific number of clinical observation hours prior to applying to their respective educational programs, this type of requirement does not yet exist in OT. However, if implemented, it could potentially help future OT students shape their professional identity earlier in the process.

Another suggestion is for OT faculty to incorporate specific learning activities that promote professional identity into the curriculum. Binyamin (2018) described a relational dilemma learning experience that was implemented at an OT school in Australia. This experience consisted of students writing case studies describing patient interactions they experienced on fieldwork, discussing conflicts and dilemmas involved in these case studies with a peer group, completing role plays, and writing a reflection. Binyamin (2018) reported that this process helped students develop a greater sense of professional identity.

It might be also important to take into consideration the fact that PA students in the current study reported having more experience than OT students with being exposed to university-based IPE activities prior to attending this event, which may have made this event less impactful for them. Additionally, because the PA and OT programs were situated on separated campuses in two different towns, the PA students were required to travel to a different campus after a long day of classes, while the OT students had the advantage of attending the event in the facility where most of their classes took place. During the debrief some of the PA students shared that the logistics of this experience had made the event less enjoyable for them, which might have affected their perceptions of their learning outcomes as a result. Physical location of the educational events and related travel logistics have been previously reported as barriers to successful IPE implementation (Rosenbloom \& Nemec, 2020).

It was also shared by the students that they preferred IPE events attended by a smaller number of professions, as it allowed them to better focus on exploring the unique contributions of other disciplines represented during the interprofessional learning experience. Faculty in charge of IPE events need to plan these experiences in a manner that does not overwhelm the students and, therefore, should consider facilitating more frequent events, each attended by a different combination of disciplines, rather than occasionally scheduling large college-wide interprofessional gatherings. 
Lastly, the participants asserted that they appreciated the opportunity to gain new clinically-based knowledge from the IPE event. Much of the literature that focuses on pedagogies aimed at improving understanding of the interdisciplinary team roles reports data only on improving teamwork and communication. This event, through its innovative TBL, Jigsaw, and clinical simulation design, augmented learning outcomes beyond the interprofessional collaboration competencies for each of the respective disciplines.

There are several strengths to these particular pedagogies. One advantage of TBL is that it requires only a few faculty members to facilitate a relatively large group of learners, such as the combination of OT and PA students. Therefore, this pedagogy allowed for this project to become a potentially ongoing, sustainable interprofessional collaboration between OT and PA programs without requiring significant resources.

"Jig-sawing" between their discipline-based and mixed interprofessional groups during the IPE event afforded the students the opportunity to discuss their unique roles and plan their discipline-specific interventions for the assigned case study within the comfort zone of their own profession prior to representing it in front of another discipline. It appears to be reasonable to suggest that this experience reinforced students' professional identities, while also allowing them to learn more about other discipline's scope of practice and engage in teamwork and cooperation, and that it enhanced their overall learning outcomes, as evidenced by the SPICE-R results.

Finally, the clinical simulation involving a patient actor embedded into the IPE event illustrated for the students how to best collaborate with a client with a specific disorder and with another discipline involved in their care, which might also have contributed to the change in their perceptions as reflected in the SPICE-R.

\section{Limitations}

There are a number of limitations to acknowledge in this report. First, while there was a good response rate and a substantial sample size, the survey only measured perceptions of one cohort at a given time. In addition, the magnitude of the impact of this event on student perceptions may have been muted as they were required to attend other IPE events throughout the year; thus, it is possible that the pre-survey was not a true measurement of baseline perceptions.

Moreover, there may be concerns as to whether the use of the gift card incentives created undue influence on response rates or perspectives; however, the monetary amount was relatively small, and the drawing process was approved by the institutional IRB.

Lastly, the original SPICE instrument was validated in pharmacists and physicians, and the SPICE-R update has been expanded to include other health professions; however, it was not validated specifically for use with an OT and PA IPE event. Additionally, the differences between groups was analyzed using multiple t-tests, which increases the likelihood of making a Type I error. Given the study design and desire to identify the 
difference between OT and PA students, analyses such as a one-way ANOVA to control for error, were not appropriate.

\section{Implications for Occupational Therapy Education}

- Strategies aimed at enhancing professional identity and assertive communication are instrumental in preparing OT students for interprofessional practice.

- Students value IPE events that offer opportunities to gain specific clinical knowledge and skills in addition to interprofessional collaboration competences.

- Innovative pedagogies, such as TBL, Jigsaw technique and clinical simulation, augment students' learning outcomes, especially when used in combination.

- IPE events attended by a smaller number of disciplines might be more conducive to interprofessional learning, as they allow learners to key into each profession's unique contributions.

- Future studies exploring the potential impact of gender-driven personality differences on both OT education and IPE initiatives might be warranted.

- Entry-level OT programs should consider requiring clinical observation hours as a part of the application process, to initiate students' professional identity development prior to enrolling in the academic curriculum.

\section{Conclusions}

This paper described the successful implementation and evaluation of an IPE event incorporating a combination of innovative pedagogies to improve OT and PA students' perceptions of core IPE competencies, as measured by the SPICE-R instrument. Authors encourage others to adopt this combination of teaching modalities, hoping for similar positive outcomes.

Both gender- and discipline-specific differences were observed among the participants' responses to this event, highlighting the importance of cultivating a strong sense of professional identity and assertive communication skills among OT students. It may benefit OT students if their educational programs include activities in the early stages of the academic curriculum that foster a sense of professional identity and allow for opportunities to practice assertive communication skills prior to engagement in IPE events with other healthcare students. For PA students, IPE events may be more impactful if the students are educated on the benefits of interprofessional collaboration prior to attending. However, the caveat should remain that what students appreciate taking away from this type of educational event the most is improved knowledge that they feel is applicable to their training as future healthcare professionals.

\section{References}

Accreditation Council for Occupational Therapy Education (ACOTE®). (2019). 2018 ACOTE standards and interpretive guide. https://acoteonline.org/wp-content/uploads/2020/07/2018-ACOTE-Standards.pdf

Accreditation Review Commission on Education for the Physician Assistant, Inc. (2019). Accreditation standards for physician assistant education (5th ed.). http://www.arc-pa.org/wp-content/uploads/2020/07/Standards-5th-Ed-Nov2019.pdf 
Avrech Bar, M., Katz Leurer, M., Warshawski, S., \& Itzhaki, M. (2018). The role of personal resilience and personality traits of healthcare students on their attitudes towards interprofessional collaboration. Nurse Education Today, 61, 36-42. https://doi.org/10.1016/j.nedt.2017.11.005

Binyamin, G. (2018). Growing from dilemmas: Developing a professional identity through collaborative reflections on relational dilemmas. Advances in Health Sciences Education, 23(1), 43-60. https://doi.org/10.1007/s10459-017-9773-2

Boehm, J., Tanner, B., Lowrie, D., Bonassi, M., Brown, N., Thomas, Y., \& Cordier, R. (2015). Exploring emerging occupational therapy identity and the development of graduate attributes among occupational therapy students. British Journal of Occupational Therapy, 78(8), 499-507. https://doi.org/10.1177/0308022614562585

Buhler, A. V., Farrell, M. K., Fuentes, D. G., Scott, B. J., Shaffer, K., \& Von, M. (2011). An interprofessional case conference on Alzheimer's disease: Teaching students in the health professional to work together. Journal of Interprofessional Care, 25(3), 223-225. https://doi.org/10.3109/13561820.2011.552813

Buhr, G.T., Heflin, M.T., White, H.K., \& Pinheiro, S.O. (2014). Using the Jigsaw cooperative learning method to teach medical students about long-term and postacute care. Journal of the American Medical Directors Association, 15(6), 429-434. https://doi.org/10.1016/j.jamda.2014.01.015

Carson, R. (2017). Relationships between student grit and Team-Based Learning preferences in a Master's level occupational therapy program. Journal of Occupational Therapy Education, 1(1). https://doi.org/10.26681/jote.2017.010105

Epstein Educational Enterprise. (2020). What is the IF-AT? http://www.epsteineducation.com/home/about/default.aspx

Fike, D. S., Zorek, J. A., MacLaughlin, A. A., Samiuddin, M., Young, R. B., \& MacLaughlin, E. J. (2013). Development and validation of the Student Perceptions of Physician-Pharmacist Interprofessional Clinical Education (SPICE) Instrument. American Journal of Pharmaceutical Education, 77(9), 190. https://doi.org/10.5688/ajpe779190

Fusco, N.M. \& Foltz-Ramos, K. (2018). Measuring changes in pharmacy and nursing students' perceptions following an interprofessional high-fidelity simulation experience. Journal of Interprofessional Care, 32(5), 648-652. https://doi.org/10.1080/13561820.2018.1496073

Gibbs, D. M., Dietrich, M., \& Dagnan, E. (2017). Using high fidelity simulation to impact occupational therapy student knowledge, comfort, and confidence in acute care. Open Journal of Occupational Therapy, 5(1). https://doi.org/10.15453/2168-6408.1225

Guadagnoli, J.A., \& Miller, T.W. (2016). Interprofessional education: A Team-Based Learning approach. Medical Science Educator, 26(3). https://doi.org/10.1007/s40670-016-0288-x

Hadley, D., Pitonyak, J., Wynarczuk, K., Sen, S., Ward, J., \& Patel, R. (2018). Experiences in teaching and learning: A pilot IPE workshop integrating OT, pharmacy, PT, and PA Programs. Currents in Pharmacy Teaching and Learning, 10(2), 220-225. https://doi.org/10.1016/j.cptl.2017.10.012 
Haracz, K., Arrighi, G., \& Joyce, B. (2015). Simulated patients in a mental health occupational therapy course: A pilot study. British Journal of Occupational Therapy, 78(12), 757-766. https://doi.org/10.1177/0308022614562792

Hertweck, M. L., Hawkins, S. R., Bednarek, M. L., Goreczny, A. J., Schreiber, J. L., \& Sterrett, S. E. (2012). Attitudes toward interprofessional education: Comparing physician assistant and other health care professions students. Journal of Physician Assistant Education, 23(2), 8-15. https://doi.org/10.1097/01367895-201223020-00003

Howell, D. (2009). Occupational therapy students in the process of interprofessional collaborative learning: A grounded theory study. Journal of Interprofessional Care, 23(1), 67-80. https://doi.org/10.1080/13561820802413281

Huszczo, G., \& Endres, M.L. (2017). Gender differences in the importance of personality traits in predicting leadership self-efficacy. International Journal of Training and Development, 21 (4), 304-317. http://dx.doi.org/10.1111/ijtd.12113

Interprofessional Education Collaborative (IPEC). (2016). Core competencies for interprofessional collaborative practice: 2016 update. https://nebula.wsimg.com/2f68a39520b03336b41038c370497473?AccessKeyld= DC06780E69ED19E2B3A5\&disposition=0\&alloworigin $=1$

Kim, Y. J., Radloff, J. C., Stokes, C. K., \& Lysaght, C. R. (2019). Interprofessional education for health science students' attitudes and readiness to work interprofessionally: A prospective cohort study. Brazilian Journal of Physical Therapy, 23(4), 337-345. https://doi.org/10.1016/j.bjpt.2018.09.003

Loftin, C., \& West, H. (2017). Evaluating self-efficacy after a Team-Based Learning activity. Official Journal of the Physician Assistant Education Association. https://doi.org/28.10.1097/JPA.0000000000000119

Manspeaker, S.A., Donoso Brown, E.V., Wallace, S.E., DiBartola, L., \& Morgan, (2017). Examining the perceived impact of an ethics workshop on interprofessional values and teamwork, Journal of Interprofessional Care, 31(5), 628-637. https://doi.org/10.1080/13561820.2017.1336992

Omura, M., Maguire, J., Levett-Jones, T., \& Stone, T.E. (2017). The effectiveness of assertiveness communication training programs for healthcare professionals and students: A systematic review. International Journal of Nursing Studies, 76. 120128. https://doi.org/10.1016/j.ijnurstu.2017.09.001

Peeters, M.J., Chen, Y., \& Sexton, M. (2016). Validation of the SPICE-R instrument among a diverse interprofessional cohort: A cautionary tale. Currents in Pharmacy Teaching and Learning, 8(4), 517-523. https://doi.org/10.1016/..cptl.2016.03.008

Risling-de Jong, R., Styron, R.A., \& Styron, J.L. (2016). Designing effective interprofessional education and collaborative practice experiences. Journal of Systemics, Cybernetics and Informatics, 14(6), 22-27. https://doaj.org/article/a6a3d3414fa1416099e6ff063b8e9ecf

Rosenbloom, S., \& Nemec, E.C. (2020). Problem-based learning and case scenarios: An interprofessional pharmacology experience. Nursing Education Perspectives. Online ahead of print. https://doi:10.1097/01.NEP.0000000000000638 
Schmitt, D.P., Long, A.E., McPhearson, A., O’Brien, K., Remmert, B., \& Shah, S.H. (2017). Personality and gender differences in global perspective. International Journal of Psychology, 52, (S1), 45-56. https://doi.org/10.1002/ijop.12265

Shoemaker, M., Platko, C., Cleghorn, S., \& Booth, A. (2014). Virtual patient care: An Interprofessional education approach for physician assistant, physical therapy and occupational therapy students. Journal of Interprofessional Care, 28(4), 365367. https://doi.org/10.3109/13561820.2014.891978

Society for Simulation in Healthcare. (2020). About Simulation. https://www.ssih.org/About-SSH/About-Simulation

South, S.C., Jarnecke, A.M., \& Vize, C.E. (2018). Sex differences in the Big Five model personality traits: A behavior genetics exploration. Journal of Research in Personality, 74, 158-165. https://doi.org/10.1016/i.jrp.2018.03.002

Team-Based Learning Collaborative. (2020). What is TBL? http://www.teambasedlearning.org/definition/

Van Soeren, M., Devlin-Cop, S., MacMilan, K., Baker, L., Egan-Lee, E., \& Reeves, S. (2011). Simulated interprofessional education: An analysis of teaching and learning processes. Journal of Interprofessional Care, 25(6), 434-440. https://doi.org/10.3109/13561820.2011.592229

Wallace, S. E., \& Benson, J.D. (2018). Bringing interprofessional case-based learning into the classroom for occupational therapy and speech-language pathology students. Occupational Therapy In Health Care, 32(1), 79-90. https://doi.org/10.1080/07380577.2017.1414975

Weidman-Evans, E., Bigler, T., Murray, L., \& Wright, C. (2017). Improving knowledge and attitudes of physician assistant and occupational therapy students using interprofessional case studies: Lessons learned. Journal of Interprofessional Education \& Practice, 6, 45-48. https://doi.org/10.1016/..xjep.2016.12.005

Weller, J.M., Boyd, M., \& Cumin, D. (2014). Teams, tribes and patient safety: Overcoming barriers to effective teamwork in healthcare. Postgraduate Medical Journal, 90, 149-154. https://doi.org/10.1136/postgradmedj-2012-131168

World Health Organization. (2010). Framework for action on interprofessional education and collaborative practice. World Health Organization Press. https://www.who.int/hrh/resources/framework action/en/

Yancey, N., Cahill, S., \& McDowell, M. (2018). Transformation in teaching-learning: Emerging possibilities with interprofessional education. Nursing Science Quarterly, 31, 126-130. https://doi.org/10.1177/0894318418755739

Zorek, J., \& Raehl, C. (2013). Interprofessional education accreditation standards in the USA: A comparative analysis. Journal of Interprofessional Care, 27(2), 123-130. https://doi.org/10.3109/13561820.2012.718295 